\title{
Effect of Specimen Thickness and Compositions on the Fracture Toughness Investigations of Al7075- SiC/Al2O3 Hybrid Composites
}

\section{A Alhadhrami}

Taif University

B M Prasanna ( $\sigma$ drbmprasanna@jitd.in )

Jain I stitute of Technology, Davanagere https://orcid.org/0000-0002-8972-5360

Saleemsab Doddamani

Jain Institute of Technology

Rajesh A M

SJM Institute of Technology

\section{Research Article}

Keywords: AA7075-SiC/Al2O3, Fracture toughness, CT specimens, Taguchi's DOE, ANOVA, Fractography

Posted Date: May 12th, 2021

DOl: https://doi.org/10.21203/rs.3.rs-506938/v1

License: (1) This work is licensed under a Creative Commons Attribution 4.0 International License.

Read Full License 


\section{Abstract}

The current work is to examine the effect of the parameters like specimen thickness, crack length to width ratio and composition of the reinforcements used in aluminium-silicon carbide/alumina particulate composite. The said composite is processed using the stir casting route. Taguchi's optimization techniques such as experiments, ANOVA and regression techniques have been utilized to investigate the parameters. Three factors and their levels considered are the composition of reinforcements $(3,6$ and 9 $w t \%)$, the thickness of specimen $(10,12,15 \mathrm{~mm})$ and a/W ratio $(0.45,0.47$ and 0.50$)$. Results show increment in composition beyond $6 \mathrm{wt} \%$, and a/W ratio decreases the fracture toughness of hybrid composites. From Taguchi's analysis, for a/W ratio $=0.45,12 \mathrm{~mm}$ thick specimens and $6 \mathrm{wt} \%$ of reinforcements in aluminium matrix exhibit the larger fracture toughness. Thus those parameters are considered to be optimized parameters. The analysis shows that the a/W ratio influences fracture toughness, followed by the composition and specimen thickness.

\section{Introduction}

Aluminium alloys of series 7XXX were utilized in commercial applications such as military air carrier due to their high strength, low weight and toughness. These alloys also possess better machinability characteristics, high wear resistance materials. Aluminium alloy 7075T6, having high strength, possess higher fracture toughness values, and have higher resistance to fatigue crack growth and thus best fit for the airframe structures such as wing skin and fuselages [1]. AA7075 T6 and AA7075 T651 have lower fracture toughness [2] values under quasi-static loading, obtained by Charpy impact testing in contrast with its value. Also, under the quasi-static loading, the fracture toughness of the smaller wide specimen is found to be lower than the larger wide fatigue cracked specimens.

The fracture toughness of the specimen in the transverse direction is lower than the longitudinal direction for anisotropic material, and its anisotropy increases with increasing thickness of specimens. Also, from the experimentation on the AA7075-T651, the crack mouth opening displacement (CMOD) for the specific crack length to width $(\mathrm{a} / \mathrm{W})$ ratio decreases with increasing thickness of the specimen [3].

Rajesh A M et al. [4-6] worked on the material characterization of AA7075-SiC/Alumina hybrid composites. The outcomes show that the said hybrid composites exhibit high strength, hardness, and elongation. Many researchers have carried out the AA7075-SiC/Alumina hybrid composites [7-8]. From the experimentation, the improved wear rate of the said composite is due to the uniform distribution of reinforcements and the better bonding with the matrix. Also, researchers conducted experiments to find the inclusion of the hard particles of the counterface in the wear testing specimens and its effect on the wear rate and the generation of mechanically mixed layer [9].

Doddamani S et al. [10-14] carried out different fracture toughness experimentations, as prescribed by the ASTM, such as CNT [10], CT [11], SENB [12] specimens, Vickers' indentations techniques [13] etc. for 
the aluminium matrix composites. Comparison of all the mentioned experimental techniques [14] concludes that each experiment back up the results obtained by other methods.

Hareesha $\mathrm{G}$ et al. [15] and Yasmin Begum et al. [16] were worked on the fracture behaviour of the AA6061$\mathrm{SiC}$ and AA6061-graphite composites using the finite element simulation using the compact tension (CT) specimens. The optimization of influencing parameters such as the thickness of specimen, crack length to width ratio, composition, and different testing techniques are carried out using Taguchi's design of experiments and ANOVA [16-17]. Comparing the experimental technique, simulation, and the statistical method [16] was also carried out for the AA6061-graphite composites.

The AA7075 matrix composites have been used in aerospace structures with high strength and wear resistance properties from the literature. However, there is scope in studying the fracture characteristics of the AA7075 matrix composites to enhance the material's crack resistance, which is the essential parameter in designing the airframe structures. Thus the key objective of the present work is to carry out the investigations of fracture toughness of AA7075-SiC/Alumina hybrid composites for different process parameters. Also, it is intended to optimize the influencing factors such as compositions, specimen thickness, and a/W ratios using Taguchi's techniques, regression analysis, and variance (ANOVA). This attempt will be made to compare the fracture toughness AA7075 matrix hybrid composites obtained from the experimental and statistical methods.

\section{Experimental}

\subsection{Materials and Preparations}

In this work, aluminium alloy 7075 is used as a matrix and particles of $\mathrm{SiC}$ and $\mathrm{Al}_{2} \mathrm{O}_{3}$ are utilized as reinforcements. The main motivation to use these materials is their density which is nearly the same such as $\mathrm{AA7075}=2.81 \mathrm{~g} / \mathrm{cc}, \mathrm{SiC}=3.1 \mathrm{~g} / \mathrm{cc}$ and $\mathrm{Al}_{2} \mathrm{O}_{3}=3.69 \mathrm{~g} / \mathrm{cc}$. Thus, the distribution of the matrix's reinforcements will become almost uniform if the composite is prepared using the liquid metallurgy process. Also, the AA7075-T6 possesses the high tensile strength $\sigma_{\mathrm{ut}}=520 \mathrm{MPa}$ and yield strength $\sigma_{\mathrm{y}}=$ $400 \mathrm{MPa}$. The $\mathrm{SiC}$ and Alumina are the types of ceramics used to withstand higher temperatures since they have higher melting points $\mathrm{SiC}\left(2730^{\circ} \mathrm{C}\right)$ and Alumina $\left(2072^{\circ} \mathrm{C}\right)$.

Therefore, the addition of $\mathrm{SiC}$ and Alumina in the AA7075 increases the tensile strength, yield strength, hardness of the composites, and they were used for applications that require high temperature withstanding capabilities.

The materials properties of the composites mainly depend on the particle size of the reinforcements. Among many other factors, the particle size of the reinforcements will significantly influence the composites' microstructure. In this work, the particle size of the reinforcements used are as follows: $\mathrm{SiC}=$ $44 \mu \mathrm{m}$ and Alumina $=60 \mu \mathrm{m}$. The said composite is prepared using the liquid metallurgy route such as stir casting technique due to its many advantages like economic, easier and uniform distribution of the 
reinforcements in the matrix [18]. The compositions used and process parameters of stir casting are cited in Table 1.

Table 1

Different composition of composites with super-heated temperature and speed

\begin{tabular}{|c|c|c|c|c|c|c|}
\hline $\begin{array}{l}\text { SI. } \\
\text { No. }\end{array}$ & AA7075 & $\mathrm{SiC}$ & $\mathrm{Al}_{2} \mathrm{O}_{3}$ & Composites & Temperature & $\begin{array}{l}\text { Stirring } \\
\text { speed }\end{array}$ \\
\hline 1 & $1 \mathrm{~kg}$ & $0.030 \mathrm{~kg}$ & $0.030 \mathrm{~kg}$ & $\begin{array}{l}\mathrm{AA7075-3 \%}(\mathrm{SiC}+ \\
\left.\mathrm{Al}_{2} \mathrm{O}_{3}\right)\end{array}$ & $720^{\circ} \mathrm{C}$ & $550 \mathrm{rpm}$ \\
\hline 2 & $1 \mathrm{~kg}$ & $0.060 \mathrm{~kg}$ & $0.030 \mathrm{~kg}$ & $\begin{array}{l}\mathrm{AA7075-6 \%}(\mathrm{SiC}+ \\
\left.\mathrm{Al}_{2} \mathrm{O}_{3}\right)\end{array}$ & $720^{\circ} \mathrm{C}$ & $550 \mathrm{rpm}$ \\
\hline 3 & $1 \mathrm{~kg}$ & $0.090 \mathrm{~kg}$ & $0.030 \mathrm{~kg}$ & $\begin{array}{l}\mathrm{AA7075}-9 \%(\mathrm{SiC}+ \\
\left.\mathrm{Al}_{2} \mathrm{O}_{3}\right)\end{array}$ & $720^{\circ} \mathrm{C}$ & $550 \mathrm{rpm}$ \\
\hline
\end{tabular}

The pieces of aluminium blocks were super-heated above their melting point (i.e. $720^{\circ} \mathrm{C}$ ) in the graphite crucible. The measured quantity of reinforcements such as $\mathrm{SiC}$ and $\mathrm{Al}_{2} \mathrm{O}_{3}$ particles $(3,6$ and $9 \mathrm{wt} \%)$ were added while stirring at the speed of 550rpm. The degasifier and the flux have been added to liquid metal to remove the gases and not absorb any gases during the pouring process. The molten hybrid composite is poured into a graphite mould and allowed for some time to solidify. This stir casting procedure is repeated for the other compositions of the hybrid composite. The solidified composite blocks were taken and machined as per the required dimensions of the compact tension (CT) specimens. While preparing the specimens, the process parameters such as specimen thickness $(10,12$ and $15 \mathrm{~mm})$ and a/W ratios $(0.45,0.47$ and 0.50$)$ were also considered.

\subsection{Experimentation}

Taguchi's design of experiments (DOE) has been utilized to optimize the fracture toughness parameters. In this work, there are three parameters, and three levels are utilized for DOE. The three factors utilized are compositions, a/W ratio and thickness of the specimen. The levels used are compositions $(3,6$ and $9 \mathrm{wt} \%), \mathrm{a} / \mathrm{W}$ ratio $(0.45,0.47$ and 0.50$)$. The thickness of the specimen considered is 10,12 and $15 \mathrm{~mm}$. For the said factors and levels, Taguchi's design of experiments has been carried out. The CT specimens have been prepared for the orthogonal array from Taguchi's design. The geometry of the CT specimen is given in Fig. 1, and Fig. 2 shows the experimental setup.

For the crack length to width ratio, i.e.,0.45, $0.47 \& 0.50$, the fatigue crack length of $1 \mathrm{~mm}, 1.6 \mathrm{~mm}$ and $2 \mathrm{~mm}$ has been introduced at the end of the V-notch in a servo-hydraulic testing machine. The experimentation has been carried out a room temperature by maintaining the $1 \mathrm{~mm} / \mathrm{min}$ of displacement rate and $5 \mathrm{~Hz}$ of frequency. The load-deformation data has been recorded, and the corresponding curves were plotted. The slop obtained in the load-deformation curves is the Type III curve [18], as indicated in Fig. 3. Type III curve indicates that the critical load $\left(P_{Q}\right)$ to be considered will be the maximum load.

\section{Results And Discussions}


Experimentation has been carried out for the Taguchi's DOE as per ASTM standard testing procedure using CT specimens. The load-displacement data has been recorded and plotted, as shown in Fig. 3. For each experiment conducted, using the obtained values of $\mathrm{P}_{\mathrm{Q}}, \mathrm{a}, \mathrm{W}$, the provisional fracture toughness $\left(\mathrm{K}_{\mathrm{Q}}\right)$ of the composite has been determined using the available standard empirical equation [11] and are listed in Table 2.

From Fig. 3, it is observed that, except for Taguchi's process parameters 6, i.e., $6 \mathrm{wt} \%$ of reinforcements, $\mathrm{a} / \mathrm{W}$ ratio $=0.50$ and specimen thickness $=10 \mathrm{~mm}$, all shows similar trends as available in the literature [10-12]. The nature of the load vs COD plot shows the ductile fracture of the AA7075-SiC/ $/ \mathrm{Al}_{2} \mathrm{O}_{3}$ hybrid composites.

Table 2

Taguchi's DOE and their fracture toughness values

\begin{tabular}{|llllll|}
\hline $\begin{array}{l}\text { Sl. } \\
\text { No. }\end{array}$ & Composition & a/W Ratio & $\begin{array}{l}\text { Specimen Thickness } \\
\mathrm{mm}\end{array}$ & Fracture Load $\left(\mathrm{P}_{\mathbf{Q}}\right) \mathbf{k N}$ & $\mathrm{K}_{\mathbf{Q}}$ \\
\hline 1 & 3 & 0.45 & 10 & 4.242 & $\mathrm{MPa} \sqrt{\mathrm{m}}$ \\
\hline 2 & 3 & 0.47 & 12 & 4.630 & 17.69 \\
\hline 3 & 3 & 0.50 & 15 & 5.008 & 17.04 \\
\hline 4 & 6 & 0.45 & 12 & 5.289 & 16.12 \\
\hline 5 & 6 & 0.47 & 15 & 5.880 & 18.38 \\
\hline 6 & 6 & 0.50 & 10 & 3.409 & 17.31 \\
\hline 7 & 9 & 0.45 & 15 & 6.516 & 16.46 \\
\hline 8 & 9 & 0.47 & 10 & 4.003 & 18.11 \\
\hline 9 & 9 & 0.50 & 12 & 4.007 & 17.67 \\
\hline
\end{tabular}

From Table 2, it is seen that the load-carrying capacity of the AA7075-SiC/ $\mathrm{Al}_{2} \mathrm{O}_{3}$ hybrid composites is high for the higher specimen thickness. In contrast, the fracture toughness is high for the lower a/W ratios. Figure 4 shows the effect of Taguchi's DOE parameters on the fracture toughness of AA7075$\mathrm{SiC} / \mathrm{Al}_{2} \mathrm{O}_{3}$ hybrid composites. The graph shows that as the a/W ratio increases, the fracture toughness of the said hybrid composites decreases. Therefore, the a/W ratio increases the crack length in the specimen increases that in turn reduces the load-carrying capacity and fracture toughness of the material. From the plot, it is also observed that, up to $12 \mathrm{wt} \%$ of reinforcements, the fracture toughness increases and further decreases for the higher wt\% reinforcements. Thus, it might be because a higher percentage of reinforcements may cause the particle grouping (clustering) in the matrix. Thus it is observed to be a decrement in the fracture toughness of the said hybrid composite. 
From Fig. 4, it is seen that thickness of the specimen has little impact on the fracture toughness. As the thickness increases from $10 \mathrm{~mm}$ to $12 \mathrm{~mm}$, the fracture toughness of the material reduces, and further increment in the thickness of the specimen does not influence the fracture toughness of the said composite. This geometry condition of the fracture toughness of the specimen is said to be the plane strain fracture toughness $\left(\mathrm{K}_{\mathrm{lc}}\right)$. Thus the critical fracture toughness $\left(\mathrm{K}_{\mathrm{Q}}\right)$ obtained is considered the plane strain fracture toughness [19] after the thickness of the specimen reaches $12 \mathrm{~mm}$. Thus the optimized parameters from Taguchi's DOE are $6 \mathrm{wt} \%$ of reinforcements, $\mathrm{a} / \mathrm{W}$ ratio $=0.45$ and specimen thickness $=$ $12 \mathrm{~mm}$.

Thus to analyze the effect of each parameter on the fracture toughness, it is required to use the ANOVA [20]. The input function for the analysis of variance is experimental fracture toughness values. For the obtained $\mathrm{K}_{\mathrm{Ic}}$ values and Taguchi's DOE, analysis of variance has been carried out, and the result of the analysis is given in Table 3 .

Table 3

Analysis of variance for fracture toughness

\begin{tabular}{|lllllll|}
\hline Source & DF & Adj SS & Adj MS & F-Value & P-Value & \% Contribution \\
\hline Composition & 2 & 0.319 & 0.160 & 01.77 & 0.362 & 05.72 \\
\hline a/W ratio & 2 & 5.060 & 2.530 & 28.02 & 0.034 & 90.74 \\
\hline Thickness & 2 & 0.017 & 0.008 & 00.09 & 0.915 & 00.30 \\
\hline Error & 2 & 0.181 & 0.090 & & & 03.24 \\
\hline Total & 8 & 5.577 & & & & 100.00 \\
\hline
\end{tabular}

From Table 3, it is observed that the a / W ratio used will have a larger influence on the fracture toughness of said composite $(90.7 \%)$, whereas the composition and thickness of the specimen have little impact. The increment in the a/W ratio means the increment in the crack length in the geometry of the specimens. Thus larger crack length reduces the load-carrying capacity, in turn, decreases the fracture toughness.

Figure 5 shows the fractography images taken from the scanning electron microscope (SEM) hybrid composites for the compositions 3, 6 and $9 \mathrm{wt} \%$ of reinforcements. From the graphs, the cracks and voids present in all the compositions of the hybrid composites. The addition of reinforcements from $3 \mathrm{wt} \%$ to $6 w t \%$ increases the barricades to crack growth and propagation, thus increasing fracture toughness. However, the larger sized voids present in the $9 \mathrm{wt} \%$ of reinforcements may arise due to the clustering [21] of the reinforced particles, which causes uneven distribution of reinforcements in the matrix. Hence, the matrix alone will not take the applied load in those locations and let voids grow bigger. The presence of these voids, on loading condition, becomes cracks that propagate and lead to the microstructure's failure. Increased size of the cracks in the microstructure of the $9 \mathrm{wt} \%$ of reinforcements causes the reduction in crack propagation resistance, thus decreases the fracture toughness of the material. Also, the fractured surface of the said composites is dull and fibrous, which specify the ductile fracture. 


\section{Confirmation Of Results}

The regression analysis has been conducted to confirm the results obtained from the experiment and Taguchi's analysis. This analysis provides the relationship between the fracture toughness and compositions, crack length to width ratio and specimen thickness. The obtained equation after the regression analysis is given below:

\section{$\mathrm{K}_{\mathrm{Ic}}=34.34+0.0589$ Composition $-36.49 \mathrm{a} / \mathrm{W}$ ratio -0.0173 Thickness eq (1)}

From the ANOVA analysis, the crack length to width ratio of the specimen influences the material's fracture toughness. Thus the eq. (1) also gives the high coefficient of a/W ratio. The negative sign of the $\mathrm{a} / \mathrm{W}$ ratio specifies increment in the $\mathrm{a} / \mathrm{W}$ ratio reduces the material's fracture toughness. The fracture toughness of the said composites is determined from Eq. (1) and are observed to be in better agreement with the experimental results (error 0.07 to $3 \%$ ) with the correlation value of 0.94 , which is said to be a perfect positive correlation.

Figure 6 shows the comparison of values obtained from the experimental and using the statistical method regression model. From Figure 6 , it is observed that the gap in between the both is lesser nearly zero for cases 4 and 6 ( $6 \mathrm{wt} \%$ of reinforcements). The error between the both is a little more for cases 1,2,3, 7 and 9 ( 3 and $9 \mathrm{wt} \%$ of reinforcements). Thus the results obtained from both the models indicate that the $6 \mathrm{wt} \%$ of the reinforcements have better fracture toughness than the said hybrid composites.

\section{Conclusions}

This work is intended to carry out the optimization of the fracture toughness parameters such as composition, crack length to width ratio and specimen thickness of the AA7075-SiC $+\mathrm{Al}_{2} \mathrm{O}_{3}$ hybrid composite. From the results obtained following conclusions were drawn:

- The experimental results show higher specimen thickness, a high load-carrying capacity, and higher $\mathrm{a} / \mathrm{W}$ ratios give the lesser fracture toughness values.

- As the composition increases, the fracture toughness increases up to $6 \mathrm{wt} \%$ of reinforcements. The increment in the specimen thickness decreases the fracture toughness up to $12 \mathrm{~mm}$ and remains nearly constant for the higher thickness, and increment in a/ $\mathrm{W}$ ratio reduces the fracture toughness. Thus the optimized parameters from Taguchi's DOE are $6 \mathrm{wt} \%$ of reinforcements, a/W ratio $=0.45$ and specimen thickness $=12 \mathrm{~mm}$.

- From the ANOVA and regression analysis, the a/W ratio influences the fracture toughness than the composition and thickness.

- From the comparison of both the models, it is observed that the $6 \mathrm{wt} \%$ of the reinforcements have better fracture toughness than the $\mathrm{AA7075}-\mathrm{SiC}+\mathrm{Al}_{2} \mathrm{O}_{3}$ hybrid composites. 


\section{Declarations}

\section{Acknowledgements}

The authors would like to thank the Ministry of education in Saudi Arabia and Taif University Researchers Supporting Project Number (TURSP- 2020/47), Taif University, Taif, Saudi Arabia. And also, thanks to Srinivas University, Mangalore, for their support.

\section{Conflict of Interest}

The authors declare that they have no conflict of interest.

\section{References}

1. Starke ER, Staley JT (1996) Application of modern aluminium alloys to aircraft, Progress Aero Sci 32: 131-172.https://doi.org/10.1016/0376-0421(95)00004-6.

2. Zinkham RE (1968) anisotropy and thickness effects in fracture of 7075-T6 and -T651 aluminium alloy. Eng Fract Mech,1: 275-289.

3. Loya JA, Fernandez SJ (2008) Three-dimensional effects on the dynamic fracture determination of Al 7075-T651 using TPB specimen, Int J Solids Struct 45: 2203-2219. https://doi.org/10.1016/j.ijsolstr.2007.11.027.

4. Rajesh AM, Mohammed Kaleemulla K, Saleemsab Doddamani (2019) Development and Characterization Of Hybrid Aluminum Metal Matrix Composites, ACTA TECHNICA CORVINIENSIS Bulletin of Engineering 12: 63-66. ISSN: 2067-3809.

5. Rajesh AM, Mohammed Kaleemulla K, Saleemsab Doddamani, Bharath KN (2019) Material characterization of $\mathrm{SiC}$ and $\mathrm{Al}_{2} \mathrm{O}_{3}$ reinforced hybrid aluminium metal matrix composites on wear behaviour, Advanced Composite Letters, SAGE, 28:1-10. https://doi.org/10.1177/0963693519856356.

6. Rajesh AM, Mohammed Kaleemulla K, Saleemsab Doddamani (2019) Effect of SiC and $\mathrm{Al}_{2} \mathrm{O}_{3}$ on wear behaviour of hybrid aluminium metal matrix composites, ACTA TECHNICA CORVINIENSIS Bulletin of Engineering 12: 43-52. ISSN: 2067-3809.

7. Rajesh AM, Mohammed Kaleemulla K, Saleemsab Doddamani (2019) Effect of heat treatment on wear behaviour of hybrid aluminium metal matrix composites, Tribology in Industry 41: 344-354. https://doi.org/10.24874/ti.2019.41.03.04.

8. Saleemsab Doddamani, Rajesh AM, Mohammed Kaleemulla K, Bharath KN (2020) Dry sliding wear simulation of hybrid aluminium metal matrix composites, Advanced Composites and Hybrid Materials, 3: 120-126. https://doi.org/10.1007/s42114-020-00133-9. 
9. Rajesh AM, Mohammed Kaleemulla K, Saleemsab Doddamani (2019) Generation of Mechanically Mixed Layer (MML) in Hybrid Aluminum Metal Matrix Composites. As-cast and Age Hardened Conditions, SN Appl Sci 1: 860. https://doi.org/10.1007/s42452-019-0906-5.

10. Doddamani, S, Kaleemulla, M (2017) Experimental investigation on fracture toughness of Al6061graphite using Circumferential Notched Tensile Specimens Frattura ed Integrità Strutturale, 11, 39 : 274-281. https://doi.org/10.3221/IGF-ESIS.39.25.

11. Doddamani S, Kaleemulla M (2017) Fracture toughness investigations of Al6061-Graphite particulate composite using compact specimens, Frattura ed Integrità Strutturale 11:484-490. https://doi.org/10.3221/IGF-ESIS.41.61.

12. Saleemsab Doddamani, Mohammed Kaleemulla, Kiran JO, Bakkappa B (2019) Fracture toughness testing of 6061Al-graphite composites using SENB specimens, Journal of The Institute of Engineers (India)-series D, Springer, 100: 195-201. https://doi.org/10.1007/s40033-019-00188-z.

13. Saleemsab Doddamani, Mohammed Kaleemulla (2016) Indentation Fracture Toughness of Alumnum6061-Graphite Composites, International Journal of Fracture and Damage Mechanics Journals Pub 1:40-46.

14. Saleemsab Doddamani, Mohammed Kaleemulla (2019) Comparisons of experimental fracture toughness testing methods of Al6061-graphite particulate composites, J of Fail Anal and Preven, 19: 730-737. https://doi.org/10.1007/s11668-019-00652-8.

15. Hareesha G, Chikkanna N, Saleemsab Doddamani (2021) Finite Element Simulation of Fracture Toughness of Al6061 Reinforced with Silicon Carbide, IOP Conference Series: Materials Science and Engineering, 1065, 012036: 1-6. https://doi.org/10.1088/1757-899X/1065/1/012036.

16. Yasmin Begum, Bharath KN, Saleemsab Doddamani, Rajesh AM, Mohamed Kaleemulla K, Optimization of process parameters of fracture toughness using simulation technique considering aluminium-graphite composites, Transactions of the Indian Institute of Metals, Springer, 73: 30953103. https://doi.org/10.1007/s12666-020-02113-5.

17. Vishal Kumar Dhummansure, Ambad Amol Kalyanrao, Saleemsab Doddamani (2020) Optimization of process parameters for fracture toughness of Al6061-graphite composites, Structural Integrity and Life, 20: 51-55. UDC: 66.018.9:539. XX. E-ISSN: 1820-7863

18. Saleemsab Doddamani, Mohammed Kaleemulla (2018) Effect of graphite on fracture toughness of 6061Al-Graphite, Strength, Fracture and Complexity, 11: 295-308. https://doi.org/10.3233/SFC180230.

19. Saleemsab Doddamani, Mohammed Kaleemulla (2019) Effect of Thickness on fracture toughness of Al6061-Graphite, Journal of Solid Mechanics 11: 635-643. https://doi.org/10.22034/jsm.2019.666695.

20. Guddhur H, Naganna C, Doddamani S (2021) Taguchi's method of optimization of fracture toughness parameters of Al-SiCp composite using compact tension specimens. An International 
Journal of Optimization and Control: Theories \& Amp; Applications (IJOCTA), 11: 152-157. https://doi.org/10.11121/ijocta.01.2021.00990.

21. Hareesha G, Chikkanna N, Anilkumar S Kallimani, Saleemsab Doddamani (2021) Effect of addition of $\mathrm{SiC}$ particles on the microstructure and hardness of $\mathrm{Al}-\mathrm{SiC}$ composite, Metallurgical and Materials Engineering, 27: 49-56. https://doi.org/10.30544/590.

\section{Figures}

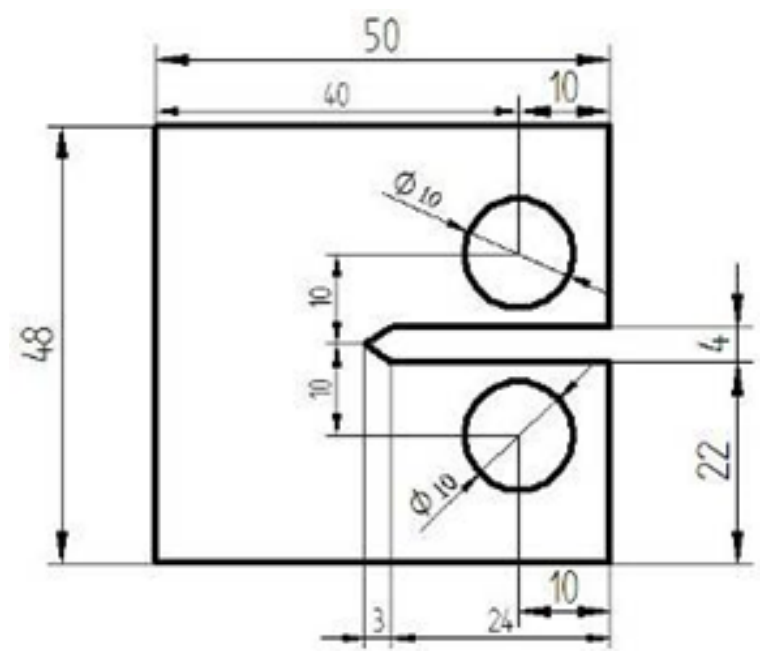

Figure 1

Geometry of the CT specimens



Figure 2 
Experimental Setup

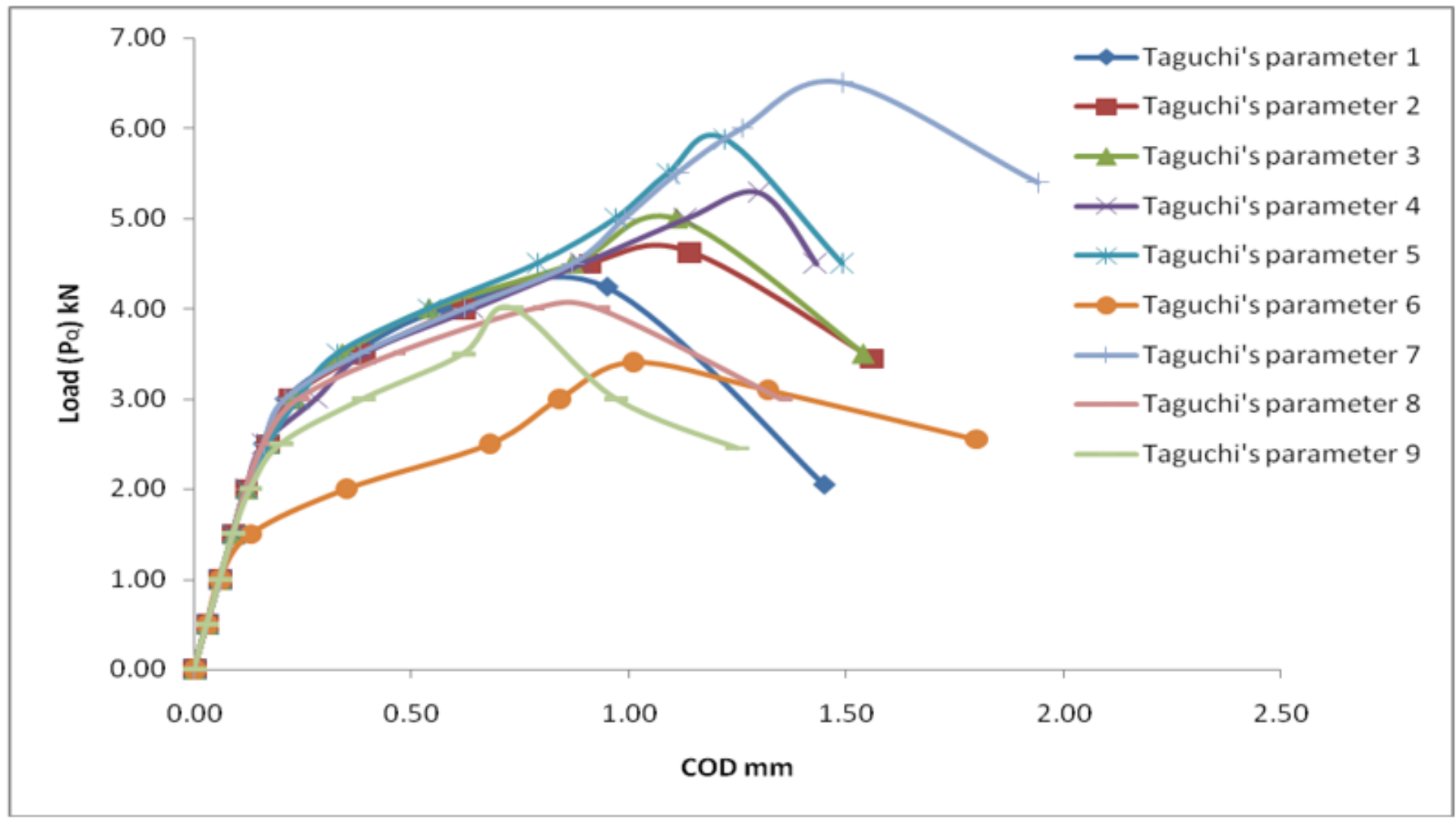

Figure 3

Load-displacement plot AA7075-SiC/Al2O3 


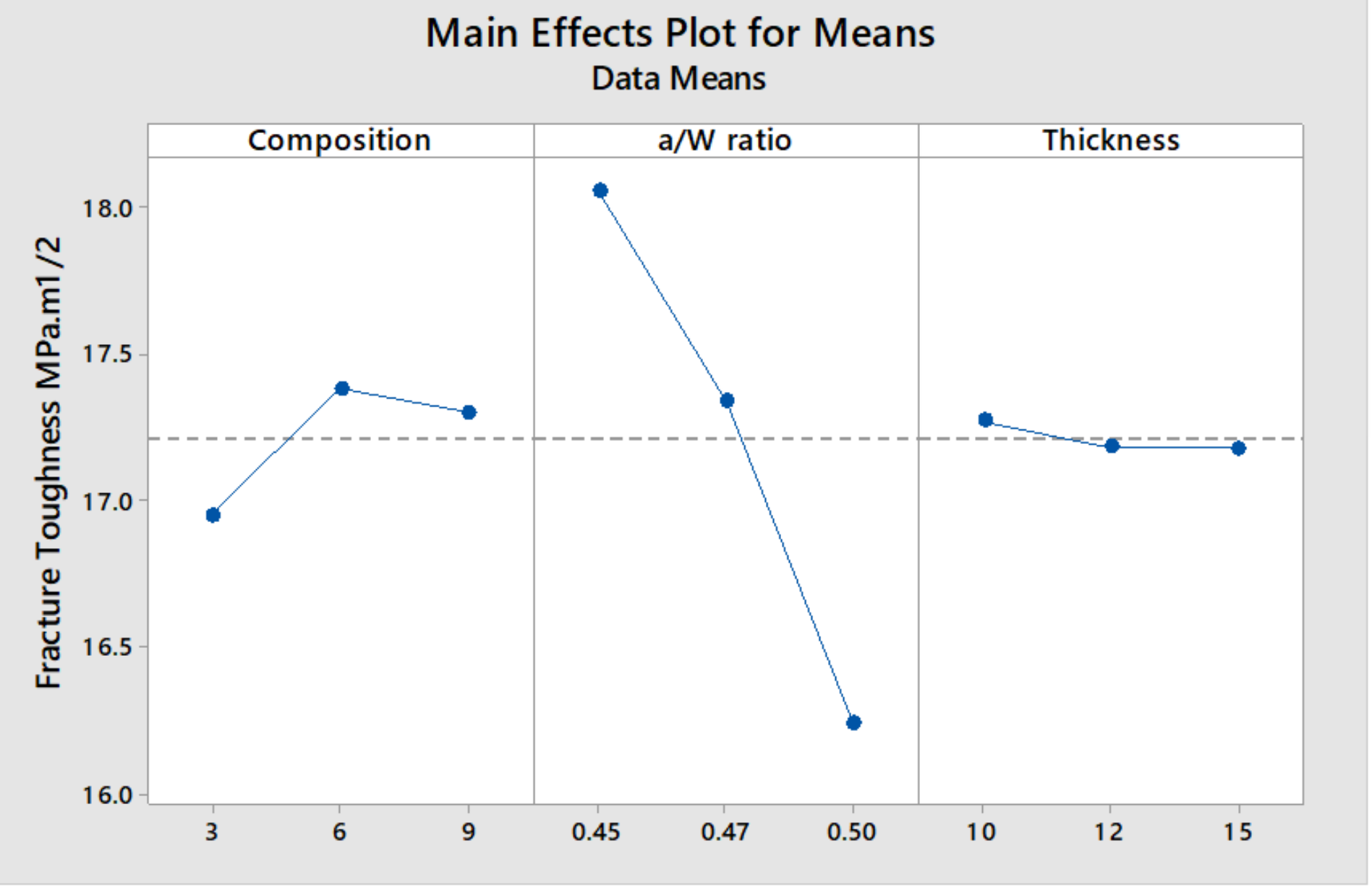

Figure 4

Effect of Taguchi's process parameters on fracture toughness 


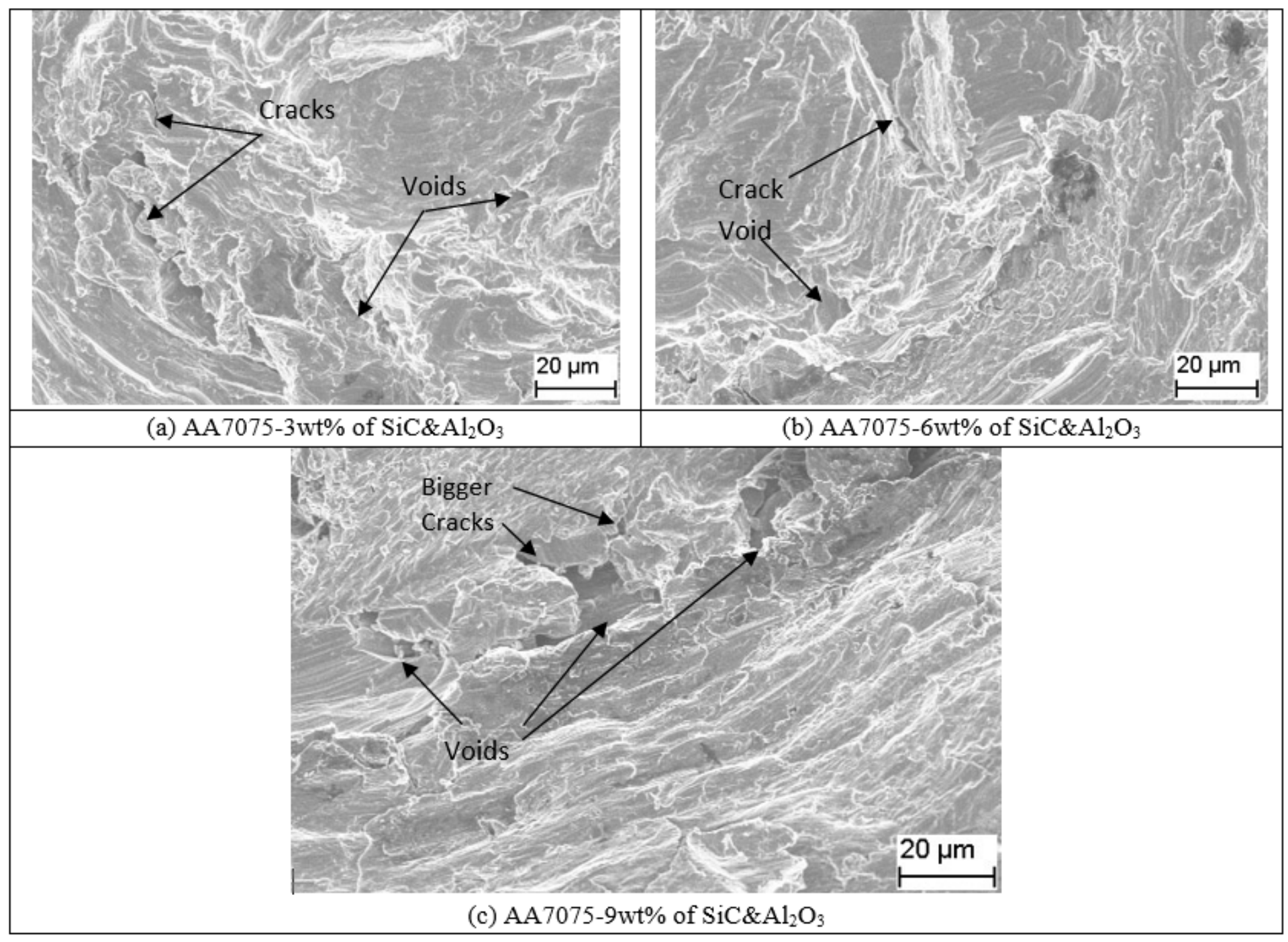

Figure 5

SEM images of fractured surfaces of the hybrid composites 


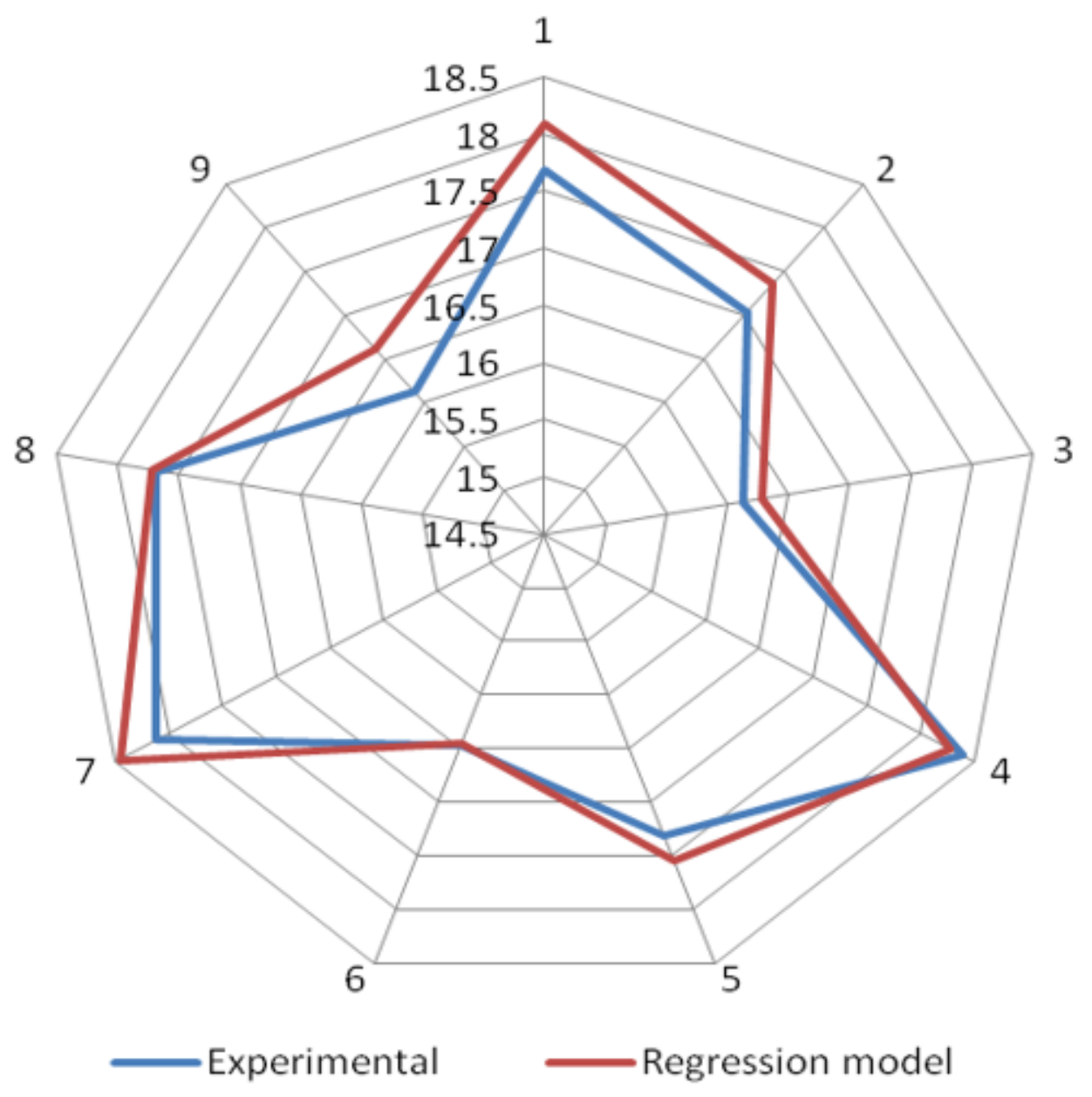

Figure 6

Comparison of experimental and analytical results of fracture toughness 